\title{
Evaluation of Effects of Positive Birth Experience on the Perception of Birth of Primiparous Women
}

duygu murat öztürk ( $\nabla$ duygu.murat@hotmail.com )

Amasya Üniversitesi https://orcid.org/0000-0001-7917-3606

\section{Saadet Gonca Mavi Aydoğdu}

Amasya Universitesi

\section{Esma Çakır}

Midwife

\section{Burcu Güler}

Midwife

\section{Research}

Keywords: Birth Perception, Positive Birth Stories, Birth, Midwifery, POBS

Posted Date: August 24th, 2020

DOI: https://doi.org/10.21203/rs.3.rs-35948/v2

License: (9) This work is licensed under a Creative Commons Attribution 4.0 International License.

Read Full License 
The authors have withdrawn this preprint from Research Square 